\author{
Saccharomyces cerevisiae와 Pichia stipitis을 이용한 \\ 댐 목질계 부유물로부터의 에탄올 생산 특성에 관한 연구 \\ 박상찬 · 장인수 · 조중식 ${ }^{11} \cdot$ 김광렬 ${ }^{1)} \cdot$ 신수정 ${ }^{2)} \cdot$ 연익준 \\ 충주대학교 환경공학과, ${ }^{1}$ 충북대학교 환경공학과, ${ }^{2}$ 충북대학교 목재종이과학과 \\ (2011년 11월 8일 접수; 2011년 11월 29일 수정; 2012년 1월 25일 채택)
}

\title{
Study on Characteristic of Ethanol Production Using Saccharomyces cerevisiae and Pichia stipitis from Woody Floater Wastes in the Dam
}

\author{
Sang-Chan Park, In-Soo Chang, Jung-Sik Cho', Kwang-Yul Kim ${ }^{1)}$ \\ Soo-Jeong Shin ${ }^{2)}$, Ik-Jun Yeon ${ }^{*}$ \\ Department of Environmental Engineering, Chungju National University, Chungju 380-702, Korea \\ ${ }^{1)}$ Department of Environmental Engineering, Chungbuk National University, Cheonju 361-763, Korea \\ ${ }^{2)}$ Department of Wood and Paper Science, Chungbuk National University, Cheongju 361-763, Korea \\ (Manuscript received 8 November, 2011; revised 29 November, 2011; accepted 25 January, 2012)
}

\begin{abstract}
Suspended wood waste was being inflow into the dam and the problem of waste disposal has been occurred. In this study, ethanol production using woody floater wastes was performed to estimate value in use for raw material of renewable energy. To achieve the goal, experiments of acid hydrolysis and ethanol fermentation using dam woody floater as raw materials for bioethanol was carried out.

In the results of field survey in the chungju dam, kind of woody floater was mainly Japanese larch (Larix leptolepis) and hybrid poplar (Populus tomentiglandulosa). The results of sugar extraction showed that sugar content was higher in Larix leptolepis than Populus tomentiglandulosa. Extracted sugar from wood waste was effective consumed by yeast $(P$. Stipitis and $S$ cerevisiae). In the experiment consumption of sugar including glucose, galactose and xylose, the consumption rate of $S$. cerevisiae is faster than that of $P$. stipitis. and efficiency for ethanol production is higer in $S$. cerevisiae than $P$. stipitis. Also it can be confirmed that resource as ethanol production using wood waste was available.
\end{abstract}

Key Words : Suspended wood waste, Hydrolysis, Sugar extraction, Yeast

\footnotetext{
*Corresponding author : Ik-Jun Yeon, Department of Environmental Engineering, Chungju National University, Chungju 380-702, Korea

Phone: +82-43-851-5359

E-mail: ijyn@cjnu.ac.kr
}

\section{1. 서 론}

산업혁명은 인류의 경제 발전 가속에 큰 원동력이 되었으나 최근 들어 이로 인한 부정적인 결과물들로 신흥개발국들의 경제발전에 따른 자원소비량 증가와 유한자원인 화석연료의 지속적인 사용에 의한 고갈로 인한 불안감 증대와 이로 인한 가격의 급등에 의한 세 
계 경제의 위기감이 고조, 그리고 화석연료의 사용으 로 인하여 지구 대기층 내 이산화탄소 배출 증가로 인 한 지구 온난화 문제가 나타나고 있다. 이러한 문제 해 결을 위하여 화석연료 사용과 탄소 배출을 감소할 수 있는 신재생에너지에 대한 관심이 커져 가고 있다 (Klass, 1998). 우리나라 또한 범지구적인 지구 온난 화에 대한 대책으로 2005 년 이산화탄소 배출 저감에 대한 교토의정서가 발효되었고 2013년 이후 우리나 라도 이산화탄소 감축 의무 이행국이 될 예정으로 온 실기체 저감효과가 높은 신 - 재생에너지 산업의 활성 화가 시급한 실정이라 할 수 있다.

신재생에너지란 기존의 화석연료를 변환시켜 이용 하거나 햇빛, 물, 지열, 생물유기체 등을 포함하는 재 생 가능한 에너지를 변환시켜 이용하는 에너지로 우 리나라에서는 8 개 분야의 재생에너지(태양열, 태양광 발전, 바이오매스, 풍력, 소수력, 지열, 해양에너지, 폐 기물에너지)와 3 개 분야의 신에너지(연료전지, 석탄 액화가스화, 수소에너지), 총11개 분야를 신재생에너 지로 지정하고 있다. 이 중 바이오매스 에너지라 함은 생물체를 구성하는 유기물을 이용하는 에너지로 농 산, 목질, 수생, 축산, 재배, 생활폐기물 바이오매스가 있으며(박 등, 2009), 이를 이용한 바이오에너지기술 은 고형 연료화, 열분해, 메탄생산을 통한 열 또는 전 기 생산 기술과 당을 포함하는 바이오매스나 유지계 바이오메스로부터 바이오에탄올이나 바이오디젤 생 산을 통한 수송용 생산기술로 크게 나뉠 수 있다(이, 2008).

이 중 목질계 매스를 이용한 바이오 에탄올 생산은 초기 사탕수수 또는 옥수수 등의 당질계 또는 전분질 계 원료로부터 바이오에탄올을 생산하는 것에 집중되 었으나 식량시장에서 곡물가격 폭등의 문제가 발생되 어 현재는 식량으로 사용이 불가능한 볏짚, 옥수수 대, 나무 등의 목질계 바이오매스를 원료로 에탄올을 생 산하는 기술 개발에 노력이 기울여지고 있다.

우리나라의 경우, 국내 목질계 바이오매스 중 재생 가능한 폐목재는 매년 임야의 개발, 가구산업 부산물 로 약 318 만톤 발생하나 현재 산림 부산물 목재의 $90 \%$, 생활, 건설, 산업분야의 폐목재 $60 \%$ 이상이 폐 기 중 이다. 또한 자연재해나 홍수로 인해 농경지, 산 림 등에서 발생한 초목류가 집중강우와 홍수시 댐에
유입되어 수자원의 오염과 수변 경관의 파괴 등과 같 은 많은 피해가 발생하고 있다(한국수자원공사, 2002; 환경부, 2001; 윤, 2004). 또 간벌 사업 후 산에 방치되 고 있는 간벌목도 홍수나 태풍 때의 집중 호우에 댐에 유입되고 있다. 이렇게 댐으로 유입되는 목질계 부유 물은 댐의 저수 능력을 저하시키고 댐에 피해를 입힐 수 있기 때문에 이를 방지하기 위하여 댐 관리 사무소 에서 목질계 댐 부유물을 분리수거 하고 있다. 따라서 분리 수거된 목질계 댐 부유물질을 신 - 재생에너지로 활용할 경우 분리 및 운반비용 측면에서 장점을 가질 수 있어 목질계 바이오매스를 활용할 수 있는 방안이 연구되어야 할 필요성이 대두되고 있다.

Cellulose, hemicellulose와 lignin이 주성분인 목질 계를 이용한 바이오에너지 생산은 목질계 바이오매스 로부터 당의 고분자인 cellulose와 hemicellulose를 분 리하고, 이를 glucose으로 분해하는 과정이 필요하다. 바이오 Refinery에서 원료로 사용될 수 있는 목재는 수 종에 따라 상당한 편차가 있지만 평균적으로 cellulose $50 \%$, hemicellulose $25 \%$, lignin $25 \%$ 정도로 구성되 어 있으며, 이를 당화하는 방법으로 암모니아 침출법 은 lignin 제거 효율이 높고 암모니아 회수가 가능하지 만 생산성이 낮고 암모니아 폭발과 증기 폭쇄법은 대 량 처리가 가능하나 수율이 낮다. 또한 SEDAP법은 hemicellulose 수율이 높고 Lime법은 처리 비용이 적 게 들지만 반응속도가 늦고 면적을 넓게 차지하는 단 점이 있다. 이 외에 가장 널리 알려진 방법으로 묽은 산(화학촉매)을 이용한 가수분해 로 산 가수분해에 의한 당화 공정은 1819년 프랑스의 화학자 Braconnot가 목재를 진한 황산으로 당화한 이후 190 여 년간 많은 연구와 공업화가 시도된 방법이다(신 등, 2009). 이런 산 당화 공정은 볏짚, 옥수수, 사탕수 수 등의 농산물계 바이오매스로부터 glucose, xylose, mannose, galactose의 단당류를 회수 할 수 있다(한국 에너지기술연구원, 2004). 당화공정을 통해 얻어진 당화액의 에탄올 생산을 위한 발효공정에는 주로 Kluyveromyces fragilis, Kluyveromyces marxianus, Zymomonas mobilis, Saccharomyces diastaticus 등의 균주가 주로 연구되고 있으며, 그 중 Brettaomyces naardenensis, Candida shehatae, Cattleya tenuis, Pichia stiptis, Saccharomyces cerevsiae와 같은 균주 
들이 큰 효과가 있는 것으로 보고되고 있다(Cho et al, 2010 ; 허 등, 1989 ; 배 등, 2010; 정 등, 1994; 신 등, 2010).

본 연구에서는 매년 다량으로 발생되고 있는 댐 목 질계 부유물질을 산 가수분해 하여 glucose을 추출한 후 Saccharomyces cerevisiae와 Pichia stipitis 의 발 효 특성을 이용한 에탄올 생산 가능성을 비교 분석 하 고자 한다.

\section{2. 재료 및 방법}

\section{1. 재료}

충주댐 상류 지역에서 홍수로 발생된 목질계 부유 물을 현장에서 수거하여 침엽수와 활엽수로 분류한 결과, 댐내 목질계 부유물질 발생비율은 침엽수 대 활 엽수 비율이 약 4: 6으로 조사되었다. 본 실험에서는 다른 목질계 부유물질을 제거한 후 낙엽송(Larix leptolepis)과 현시나무(Populus tomentiglandulosa) 만을 이용하여 혼합비율에 따른 에탄올 생산 특성을 비교하기 위해 혼합비율을 $10: 0,3: 7,4: 6,5: 5,0: 10$ 로 하여 실험을 실시하였다. 실험에 사용된 시료는 4 개월 동안 건조된 목재를 칩으로 제조한 다음 Wiley mill을 사용하여 $20 \mathrm{mesh}$ 이하 크기로 미세분말을 만든 후 다 시 공기 중에서 함수율 $14 \%$ 이하로 건조 시켰으며, 이 를 실험에 이용하였다.

\section{2. 방법}

목질계바이오매스를 이용한 바이오에탄올 생산을 위해서는 당화과정과 발효과정이 필요하다. 본 연구 에서는 황산을 이용한 산가수분해를 통한 당화를 진 행하였으며, 에탄올 생산을 위한 발효를 위해 주로 이 용되는 효모(yeast) 중 Saccharomyces cerevsiae SIV-89와 Pichia stiptis KCCM 12009를 선정하여 실 험을 수행하였다.

\subsection{1. 산가수분해}

$72 \%$ 황산 $(24.0 \mathrm{~N}, 37.5 \mathrm{ml})$ 과 목분 (건조 중량 $25.0 \mathrm{~g}$ )과 1 차 가수분해 반응을 시킨 후 $30{ }^{\circ} \mathrm{C}$ 에서 한 시간 동안 1 차 가수분해하고 첨가한 황산의 2.45 배(질 량 비)에 해당 하는 끓는 물을 첨가하여 $105{ }^{\circ} \mathrm{C}$ 에서 한 시간 동안 2 차 가수분해 반응을 실시하였다. 2 차 가수
분해 반응을 마친 후 반응 용기를 냉각수에서 냉각시 킨 후 여과하여 당화 액을 수집하였다. 강산 당화 액의 중화를 위하여 수산화칼슘과 탄산칼슘을 사용하여 황 산을 중화하여 황산 칼슘형태의 침전으로 산을 제거 하였다. 당화액과 황산칼슘 침전물의 혼합물을 감압 상태에서 여과하여 당화 액(액상)과 황산칼슘 침전물 (고상)을 분리하였다. 중화 액의 $\mathrm{pH}$ 가 5.5-7.5 범위에 도달했을 때 중화를 멈추었다.

\subsection{2. 산가수분해 당화액 분석}

산 가수분해 중화액내 glucose, xylose, galactose는 액체 크로마토그래프 (Agilent model 1200 liquid chromatography)로 분석하였다. glucose 분석은 Aminex HPX-87H (300mm x 7.8mm, BIO-RAD) 컬 럼과 굴절률 검출기 (Refractive Index Detector)를 사 용하였고, 이동상으로는 $5 \mathrm{mM}$ 황산, 유속은 0.6 $\mathrm{mL} / \mathrm{min}$, 컬럼 온도는 $45^{\circ} \mathrm{C}$ 이었다.

\subsection{3. 발효}

본 실험에서 발효 균주로 사용된 S. cerevisiae와 $P$. stipitis 는 종균배지에서 18 시간 배양한 후 본 배양배 지에 접종하였다. 종균배지의 조성은 glucose $10 \mathrm{~g} / \mathrm{L}$, yeast extract $3 \mathrm{~g} / \mathrm{L}$, malt extract $3 \mathrm{~g} / \mathrm{L}$, peptone $5 \mathrm{~g} / \mathrm{L}$ 이며, 에탄올을 생산하기 위한 본 배지의 조성은 glucose $95 \mathrm{~g} / \mathrm{L}$, xylose $21 \mathrm{~g} / \mathrm{L}$, yeast extract $5 \mathrm{~g} / \mathrm{L}$, peptone $5 \mathrm{~g} / \mathrm{L}, \mathrm{K}_{2} \mathrm{HPO}_{4} 1 \mathrm{~g} / \mathrm{L}, \mathrm{MgSO}_{4} 1 \mathrm{~g} / \mathrm{L}$ 이다. 각 배지의 초기 $\mathrm{pH}$ 는 $1 \mathrm{~N} \mathrm{HCl}$ 과 $\mathrm{NaOH}$ 를 이용하여 6.0 으로 조정하였으며, 완충액은 사용하지 않았다. 본 배 양은 배지 $50 \mathrm{~mL}$ 을 포함하고 있는 $250 \mathrm{~mL}$ 플라스크 에서 진탕 배양기를 이용하여 $200 \mathrm{rpm}, 30{ }^{\circ} \mathrm{C}$ 에서 72 시간 배양하였다.

\subsection{4. 발효액분석}

발효 중 일정 시간마다 발효액을 채취한 후 액체 크로 마토그래프 (Agilent model 1200 liquid chromatograph) 로 분석하였다. Aminex HPX-87H (300mm x 7.8mm, $\mathrm{BIO}-\mathrm{RAD}$ ) 컬럼과 굴절률 검출기 (Refractive Index Detector)를 사용하였고, 이동상으로는 $5 \mathrm{mM}$ 황산, 유 속은 $0.6 \mathrm{~mL} / \mathrm{min}$, 컬럼 온도는 $45^{\circ} \mathrm{C}$ 로 하였다. 


\section{3. 결과 및 고찰}

\section{1. 산 가수분해에 의해 생산된 당화액 분석}

충주댐에서 수거한 목질계 부유물을 이용한 에탄 올 생산 가능성을 평가하기 위해 먼저 산가수분해에 의한 당화실험을 수행하였다. Table 1 에 보여진 바와 같이 활엽수인 현사시나무와 침엽수인 낙엽송의 혼합 비에 따른 당화액의 LC분석 결과, glucose의 농도는 현사시나무와 낙엽송에서 각각 $37.3 \mathrm{~g} / \mathrm{L}$ 와 $44.2 \mathrm{~g} / \mathrm{L}$ 이 었으며, xylose와 galactose 혼합물 농도는 현사시나무 에서는 $19.0 \mathrm{~g} / \mathrm{L}$, 낙엽송에서 $24.5 \mathrm{~g} / \mathrm{L}$ 이었다. Glucose, xylose와 galactose 혼합물 모두에서 낙엽송의 혼합비 율이 증가할수록 농도가 하는 경향을 보여 총 glucose 의 농도 역시 같은 경향성을 보였다. 그러나 glucose 발효를 저해할 수 있는 물질인 아세트산의 농도는 현 사시나무에서 $6.3 \mathrm{~g} / \mathrm{L}$, 낙엽송에서 $2.5 \mathrm{~g} / \mathrm{L}$ 으로 낙엽송 의 혼합비가 증가할수록 점차 낮아지는 경향을 보였 다. 현사시나무에서 산 당화액내 아세트산의 농도가 낙엽송보다 높은 것은 황 등(2005)에서 보고된 바와 같이 활엽수의 자이란 사슬에 아세틸기의 치환도가 높은 특성에 의해 상대적으로 높은 acetic acid의 농도 를 보이는 것으로 판단된다(황 등, 2005).

\section{2. 효모균주을 이용한 에탄올 발효}

3.2.1. 발효 균주에 따른 Glucose 소비

발효진행에 대한 상대적 기준이 될 수 있는 glucose 소모율의 측정을 위해 S. cerevisiae와 P. stipitis에 의 한 glucose의 농도변화를 측정하여 보았다. $S$. cerevisiae에 의한 glucose소비는 현사시나무, 낙엽송 그리고 침엽수와 활엽수를 혼합비율에 따른 당화액 시료 모두에서 발효 시작 24 시간 이내에 빠르게 소비 되었다. 그러나 P. stipitis에 의한 glucose소비는 낙엽
송의 경우 발효 시간 48 시간지난 후에야 대부분 소비 되었으며, 현사시나무의 혼합비가 높은 시료일수록 소비시간이 길어져 현사시나무 당화액의 경우 약 80 시간 경과 후 소비되는 경향을 보였다. 이 결과는 $S$. cerevisiae는 아세트산의 glucose의 분해 큰 영향을 받 지 않으나, P. stipitis의 경우 아세트산에 의한 glucose 의 발효 저해가 발생되는 기존 연구와 일치하는 결과 를 보였다(Cho 등, 2010).

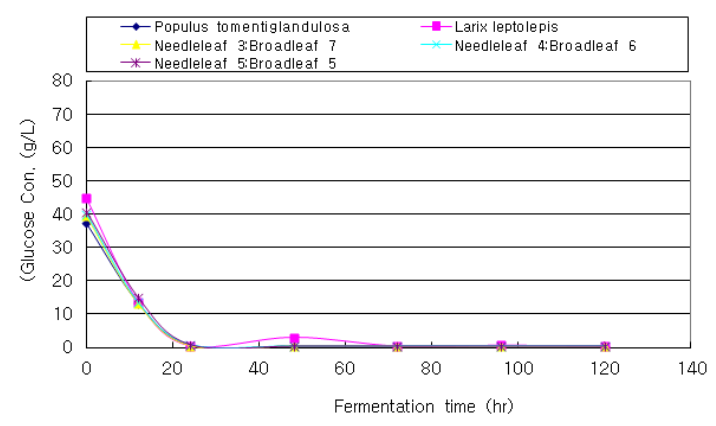

Fig. 1. Consumption of glucose during fermentation time by S. cerevisiae.

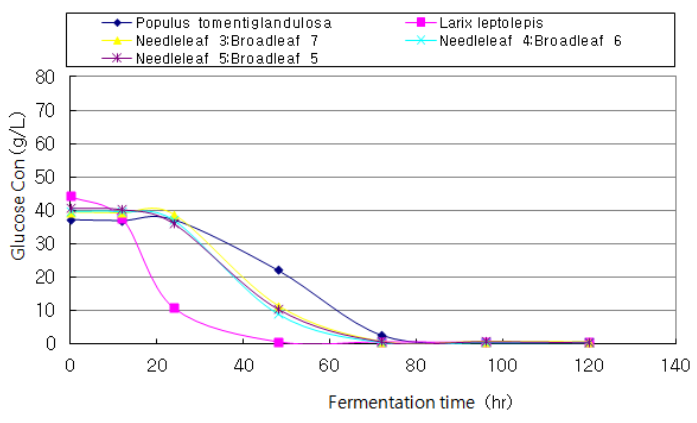

Fig. 2. Consumption of glucose during fermentation time by P. stipitis.

Table 1. Chemical composition of acid hydrolysate

(Unit: g/L)

\begin{tabular}{ccccc}
\hline $\begin{array}{c}\text { Mix ratio } \\
\text { (P. tomentiglandulosa : Larix leptolepis) }\end{array}$ & Glucose & $\begin{array}{c}\text { xylose and } \\
\text { galactose }\end{array}$ & Total sugar & acetic acid \\
\hline \hline P. tomentiglandulosa & 37.3 & 19.0 & 56.3 & 60.2 \\
\hline $3: 7$ & 39.5 & 20.7 & 60.7 & 6.3 \\
\hline $4: 6$ & 39.7 & 21.0 & 62.4 & 4.5 \\
\hline $5: 5$ & 40.7 & 21.7 & 68.7 & 2.5 \\
\hline L. leptolepis & 44.2 & 24.5 & & \\
\hline
\end{tabular}


3.2.2. 발효 균주에 따른 Xylose와 Galactose 소비

S. cerevisiae와 P. stipitis를 이용한 당화액 발효 시 xylose와 galactose의 소비경향을 조사하여 Fig.3과 Fig. 4에 나타내었다. (황 등,2005)와 (박 등, 1994)에 따르면 침엽수와 활엽수 내 Hemicellulose의 주성분 은 각각 (galacto)glucomannan와 4-o-methylglucuronoxylan으로 낙엽송은 galactose 함량이 높고 현사시 나무는 xylose 함량이 상대적으로 높은 특성을 보이는 것으로 알려져 있다. 본 실험에서는 $\mathrm{LC}$ 를 이용한 분 석 시 xylose와 galactose를 분리하지 못하여 당화액 내 galactose와 xylose 혼합물의 농도를 나타내었으나 기존 연구에 의한 결과를 기초를 통해 xylose와 galactose 소비경향을 분석하여 보았다.

Fig. 3의 S. cerevisiae에 의한 xylose와 galactose의 소비경향 결과는 5 탄당인 xylose를 분해하지 못하는 S. cerevisiae의 xylose와 galactose 발효특성을 잘 나 타내고 있다. xylose 함량이 상대적으로 높은 특성을 보이는 활엽수인 현사시나무 당화액의 발효 시 낮은 xylose와 galactose 혼합물 농도에도 불구하고 발효진 행 시간의 경과에 따라 상대적으로 낮은 xylose와 galactose 혼합물의 소비가 이루어지며(신 등, 2010), galactose의 함량이 상대적으로 높은 침엽수의 혼합비 가 높아질수록 상대적으로 galactose의 농도가 높아져 침엽수인 낙엽송 당화액을 이용한 실험에서는 초기 xylose와 galactose 혼합물의 농도가 높음에도 불구하 고 발효 시간의 경과에 따라 xylose와 galactose 혼합 물에 대해 높은 소비가 이루어지는 것으로 나타났다. S. cerevisiae에 의한 당화액 중 xylose와 galactose 혼 합물의 소비 결과, xylose와 galactose 혼합물의 소비 경향은 galactose가 소비됨에 따라 24시간 이내까지 는 급격하게 소비되는 것으로 나타났으나 이 후 급격 하게 발효속도가 느려지는 경향을 나타내었는데 이는 galactose의 소비로 인한 농도 감소 후 xylose가 주로 존재하여 S. cerevisiae에 의한 발효가 진행되어지지 않기 때문인 것으로 보인다. 반면 Fig. 4에 보여진 바 와 같이 xylose를 탄소원으로 이용하여 에탄올을 생산 할 수 있는 P. stipitis는 초기 xylose와 galactose 혼합 물의 농도가 천천히 감소하나 120 시간까지 지속적으 로 소비되는 경향을 보였다(Toivola 등, 2004).

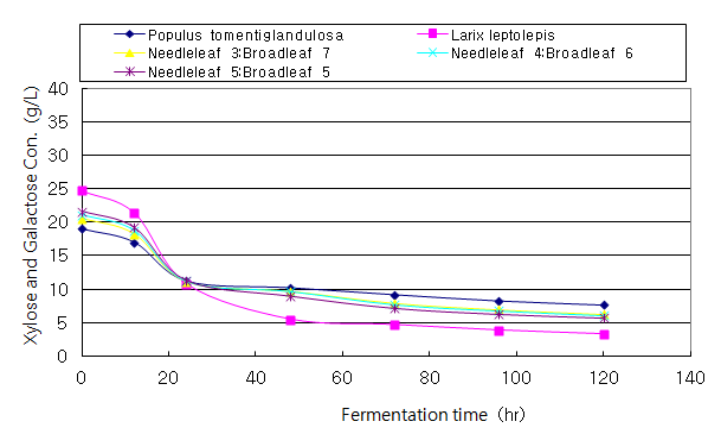

Fig. 3. Consumption of xylose and galactose during fermentation time by $S$. cerevisiae.

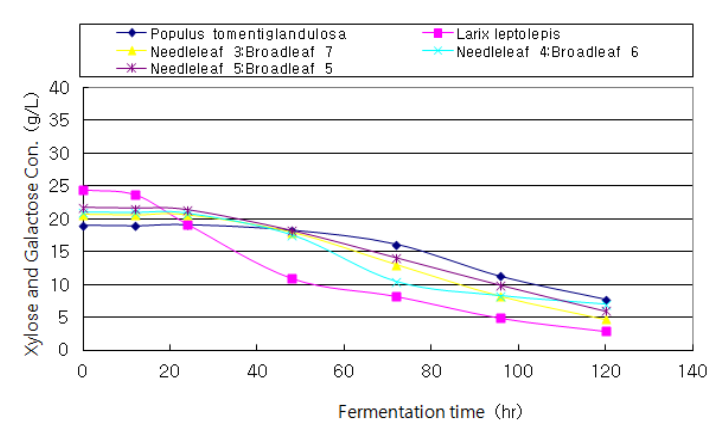

Fig. 4. Consumption of xylose and galactose during fermentation time by $P$. stipitis.

\subsection{3. 발효 균주에 따른 전체당 소비}

(Toivola 등, 2004)에 따르며 P. stipitis는 $20 \mathrm{~g} / \mathrm{L}$ 의 xylose를 탄소원으로 공급 시 $1.0 \mathrm{~g} / \mathrm{L}$ 이상의 에탄올을 생산할 수 있는 것으로 알려져 있으나 xylose의 전환 율과 에탄올 수율의 개선을 위해 많은 연구가 이루어 져야 하는 과제가 남겨져 있다. Fig. 5와 6에 보여진 바와 같이 S. cerevisiae와 P. stipitis 를 이용한 목질계 당화액의 발효 실험 결과, 비록 산 가수분해에 의해 생 산되는 당화액 내 존재하는 xylose는 P. stipitis에 의 해 발효가 진행되어 지나 전환율이 낮아 전체적인 glucose 소비에 대한 분석 결과에서 큰 차이를 보이지 않았다. 또한 $S$. cerevisiae는 당화액 내 glucose 소모 에 의한 발효 진행이 24 시간이내에 진행되어지나 $P$. stipitis에 의한 당화액 내 glucose 소모에 의한 발효는 초기 반응 24시간 이내까지 매우 느린 속도로 진행되 며 이후 반응이 지속적으로 진행되어 약 96 시간 경과 후 S. cerevisiae와 유사한 결과를 나타내었다. 


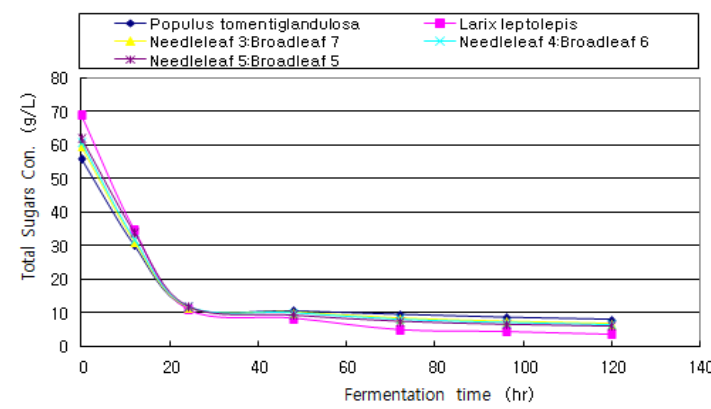

Fig. 5. Consumption of total sugar during fermentation time by $S$. cerevisiae.

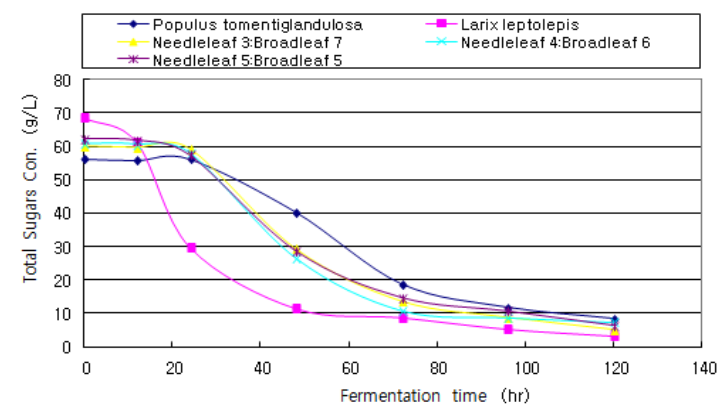

Fig. 6. Consumption of total sugar during fermentation time by $P$. stipitis.

\subsection{4. 발효 균주에 따른 에탄올 생산}

산 가수분해를 통해 얻어진 당화액의 발효를 통해 얻어지는 에탄올의 농도를 조사하여 Fig. 7과 8에 나 타내었다. Fig. 7에 보여진 바와 같이 S. cerevisiae가 발효 진행 시 초기 에탄올의 농도가 급격히 높아져 24 시간 이내에 에탄올이 급격히 생산되어지는 것어지며, 48시간 경과 후 현사시나무와 낙엽송의 혼합비에 따라 $20.3 \sim 26.8 \mathrm{~g} / \mathrm{L}$ 의 농도를 보이나 이후에는 에탄올 농도 가 점차적으로 감소하여 $17.2 \sim 23.7 \mathrm{~g} / \mathrm{L}$ 의 농도를 나타 내었다. 이는 에탄올 소비가 가능한 S. cerevisiae가 단 당이 소비되어 에너지원이 부족해지면 에탄올을 소 비하기 때문에 시간이 지나면서 에탄올 농도가 떨어 지는 것으로 판단된다. 반면 Fig 9에 보인 바와 같이 P. stipitis에 의한 ethanol 생산은 72시간 이내에 $19.0 \sim 27.2 \mathrm{~g} / \mathrm{L}$ 의 에탄올 생산되는 것으로 나타났다.

현사시나무와 낙엽송의 혼합비에 따라 생산되어지 는 에탄올의 농도 비교 결과, 낙엽송의 혼합비가 높을
수록 에탄올의 생산농도가 높게 나타났다. 이는 낙엽 송에 발효되기 쉬운 glucose와 galactose 등의 당 함량 이 높기 때문에 에탄올 농도가 높은 것으로 보이며, 반 면 S. cerevisiae에 의해 발효에 이용되어지지 않거나 P. stipitis에 의해 발효에 이용되지만 전환율이 낮은 xylose 함량이 높은 활엽수는 glucose 농도가 높더라 도 최종 에탄올 농도가 침엽수에 비하여 떨어지게 되 는 것으로 판단된다(황 등, 2005; 박 등, 1994). 또한 $S$. cerevisiae와 P. stipitis의 발효 특성을 종합하여 볼때 에탄올 생산성은 P. stipitis보다 S. cerevisiae가 더 우 수한 것으로 나타났다. 따라서 충주댐 목질계 부유물 을 이용한 에탄올 생산 시 P. stipitis보다 S. cerevisiae 의 이용이 보다 효율적일 것으로 판단된다.

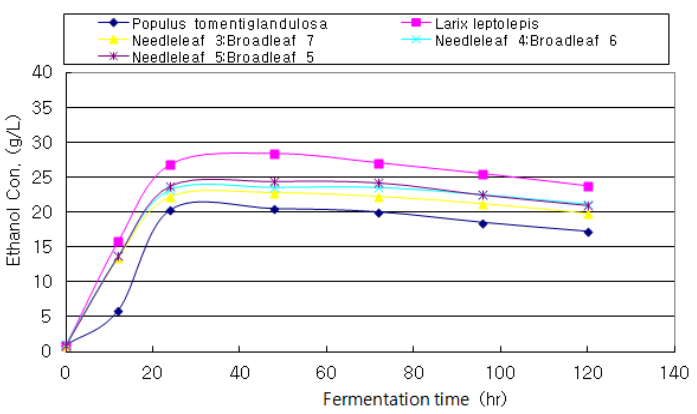

Fig. 7. Production of ethanol by S. cerevisiae.

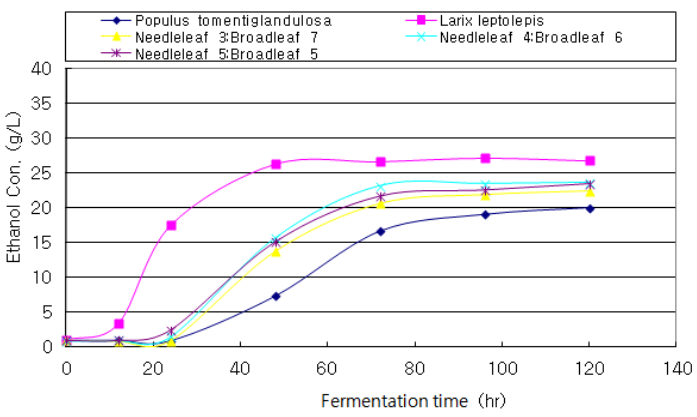

Fig. 8. Production of ethanol by P. stipitis.

\section{4. 결 론}

목질계 바이오매스 재활용을 통한 신 - 재생에너지 로의 생산 가능성을 알아보기 위해 충주 댐 목질계 부 유물을 원료로 에탄올 생산 연구의 결과, 다음과 같은 
결론을 얻었다.

4.1. 현사시나무와 낙엽송의 혼합비의 변화에 따른 시료에 대한 당화액 추출 결과, 현사시나무에 비해 낙 엽송에서 높은 농도의 glucose를 추출할 수 있었으며, $\mathrm{LC}$ 분석 결과 현사시나무로부터 추출된 당화액은 낙엽 송에 비하여 높은 아세트산 농도를 나타내었다.

4.2. 현사시나무, 낙엽송, 혼합시료로부터 얻어진 모 든 당화액 중에 존재하는 glucose는 S. cerevisiae에 의 해 24시간 이내 빠르게 소비되어지는 반면 P. stipitis에 의한 glucose소비는 낙엽송의 경우 발효 시간 80 시간 지난 후에야 대부분 소비되었다.

4.3. 당화액 중 존재하는 Xylose와 galactose 혼합 물 소비에 대한 관찰 결과, xylose를 탄소원으로 사용 하지 못하는 S. cerevisiae는 24시간 내에 급격하게 galactose만을 소비하는 것으로 나타났으며, xylose를 탄소원으로 이용하여 에탄올을 생산할 수 있는 $P$. stipitis는 초기 xylose와 galactose 혼합물의 농도가 천 천히 감소하나 120 시간까지 지속적으로 소비되는 경 향을 나타내었다.

4.4. 전체 glucose 소비는 S. cerevisiae가 P. stipitis 보다 빠르게 나타나 에탄올 생산은 24시간에 거의 최 고 농도의 에탄올 생산이 가능한 것으로 나타났으며, P. stipitis에 의한 에탄올 생산은 낙엽송의 경우 72 시 간 이내에 최고 농도의 에탄올 생산이 가능할 것으로 나타났다.

이상의 결과들을 종합해 볼 때 충주댐 목질계 부유 물질을 이용하여 에탄올 생산이 가능할 것으로 판단되 며 에탄올을 생산할 경우 P. stipitis보다 S. cerevisiae 를 사용하는 것이 더 효율인 것으로 나타났다.

\section{감사의 글}

논문은 2010년도 충주대학교 교내학술연구비의 지 원을 받아 수행한 연구입니다.

\section{참 고 문 헌}

박경목, 김동찬, 이종윤, 양재경, 유창현, 정원일, 1994, 침엽수 톱밥에서 표고 균사생장 촉진에 관한 연구, 한국균학회, 22(3), 222-228.

박수남, 구재희, 임용택, 허려화, 서용교, 이일규, 하후찬, 2009 , 목질계 바이오매스 숯 생산 공정에서 발생하 는 열분해가스 생산 특성, 한국신·재생에너지학회 춘계학술대회논문집, 443-446.

배양원, 성필제, 조대행, 신수정, 김승욱, 한성옥, 김용환, 박정환, 2010, P. stipitis를 이용한 리그노셀룰로스 계 바이오매스 기반의 바이오에탄올 생산, 한국생물 공학회지, 25, 533-538.

신수정, 박종문, 조대행, 김용환, 조남석, 2009 , 백합나무 를 이용한 고농도 단당류 생산을 위한 산 가수분해 특성연구, 목재공학, 37(6), 578-584.

신현석, 강성우, 이상준, 장은지, 서영웅, 김승옥, 2010, 고정화 P. stipitis를 이용한 글루코오스자일로오스 혼합당으로부터 에탄올생산, 한국생물공학회, 25 , 351-356.

윤석표, 2004, 충주댐 부유물질 발생현황 조사 및 처리대 책, 충북지역환경기술개발센터.

이진석, 2008 , 지식경제부, 에너지관리공단 신·재생에너 지센터, 신·재생에너지 백서: "바이오", 344-363.

정봉환, 유연우, 서진호, 1994 , 오탄당과 육탄당의 혼합 용액에서 P. stipitis에 의한 에탄올 발효, 한국생물공 학회지, 9(4), 395-399.

한국수자원공사, 2002, 2002년 집중강우시 부유쓰레기 수거처리분석에 따른 부유쓰레기 종합대책.

한국에너지기술연구원, 2004, 목질계 바이오매스의 고 효율 당화 공정 개발을 위한 핵심 요소기술 연구, 산 업자원부.

허병기, 김현성, 목영일, 1989 , 효모 S. cerevisiae의 돼지 감자 알콜발효 특성과 발효시간과의 함수관계, 한국 생물공학회지, 4(2), 191-196.

환경부수질보전국, 2001 , 주요댐 부유쓰레기 저감대책.

황병호, 윤병호, 조남석, 이종윤, 2005, 최신 목재화학, 선 진문화사, 18-19.

Cho, D. H., Shin, S. -J., Bae, Y., Park, C., Kim, Y. H., 2010, Enhanced ethanol production from deacetylated yellow poplar acid hydrolysate by Pichia stipitis, Bioresour. Technol., 101(13), 4947-4951.

Klass, D. L., 1998, Biomass for renewable energy, fuels and chemicals, Academic Press, San Diego, 495-497.

Toivola, A., D., Yarrow, E., Van den Bosch, J. P., Van Dijken, Scheffers, W. A., 2004, Ethannolic fermentation of D-xylose by yeasts, Appl. Environ. Microbiol, 47, 1221-1223. 